\title{
Intermodal and inter-genre translation in scientific writing
}

Claude Sionis

\section{(2) OpenEdition \\ Journals}

Electronic version

URL: http://journals.openedition.org/asp/2112

DOI: $10.4000 /$ asp. 2112

ISBN: 978-2-8218-0382-4

ISSN: 2108-6354

Publisher

Groupe d'étude et de recherche en anglais de spécialité

Printed version

Date of publication: 31 December 2000

Number of pages: $185-198$

ISSN: 1246-8185

\section{Electronic reference}

Claude Sionis, « Intermodal and inter-genre translation in scientific writing », ASp [Online], 27-30 | 2000,

Online since 28 January 2011, connection on 03 May 2019. URL : http://journals.openedition.org/ asp/2112 ; DOI : 10.4000/asp.2112

This text was automatically generated on 3 May 2019.

Tous droits réservés 


\title{
Intermodal and inter-genre translation in scientific writing
}

\author{
Claude Sionis
}

\section{Definitions and methodological framework}

1 The notions ${ }^{1}$ of 'mode' and 'genre' probably need to be defined unequivocally. By 'modes of representation' I mean verbal or semi-verbal texts, photographs, tables, flow-charts, etc. By 'genres of representation' I mean a written paper, a discussion, a research note, an oral presentation, etc.

2 The methodological approach chosen is that of the interactionist school among the sociology of science (Straus \& Rainwater 1962; Fujimora 1987, 1992; Star \& Griesemer 1989). For these researchers and for others, who insist on the 'constructivistic' aspect of science (Callon \& Latour 1991; Latour \& Woolgar 1988; Amman \& Knorr 1988), scientific activity is composed of projects (solving a problem, going beyond a technical limit, etc.). Each project follows a route, is characterised and made meaningful by this route. But this meaning is not known in advance, it cannot be equated with the initial purpose of the researchers, the interests of the research group, scientific logic or nature: it results from the route followed (Vinck 1995). Now this route itself results from a number of multiple interactions between scientists and between scientists and lay persons, their work, their different perspectives, the conditions which structure their interactions and the occurring events. As Lynch (1985) observed, scientific facts result directly from the investigation which produces them and cannot be dissociated from the investigation process.

3 My claim here is that the route followed by a project is also influenced by the modes of representations and the constraints belonging to several genres which make up the way scientists express their work within and without their research communities. Significations are then constructed by approximations, interactions and collective action (remedial, tinkering, trial-and-error, etc.). This approach makes it possible for local 
scientific problems to be dealt with in relative isolation and for global problems to be tackled gradually.

4 If the ultimate and global representational genre is the printed RA, each of its constitutive steps reflects a locally solved problem which has to be processed with the tools appropriate at the time it crops up, e.g., by rephrasing a sentence misunderstood by a fellow-researcher during a discussion session. This process, or a reflection of it, then has to be 'translated' into the nearest possible written mode within the genre of an RA, e.g., a real-life demonstration using everyday objects (see later) is translated as a chunk of written text associated with a series of photographs.

\section{The EAP situation}

5 The study is based on an English for Academic Purposes (EAP) course for established French researchers on how to write research articles (RAs) in English. The rather conventional plan of the course followed the canonical IMMRD pattern (Introduction, Materials and Method, Results, Discussion) and can be summarised in table 0 .

Table 0. Plan of the EAP course

\begin{tabular}{|c|c|c|}
\hline & & 20 hours \\
\hline 1 & Generalities & \\
\hline 2 & $\begin{array}{l}\text { Introductions, } \quad \text { Moves and } \\
\text { submoves }\end{array}$ & $\begin{array}{l}\text { Language technique: how to speak of purpose and } \\
\text { strategy }\end{array}$ \\
\hline 3 & $\begin{array}{l}\text { Materials \& Methods, Moves and } \\
\text { submoves }\end{array}$ & Language technique: how to define concepts \\
\hline 4 & Results, moves and submoves & $\begin{array}{l}\text { Language technique: linking words and phrases; } \\
\text { comparing and evaluating }\end{array}$ \\
\hline 5 & Discussion, Moves and submoves & $\begin{array}{l}\text { Language technique: adverbs, modality, asking } \\
\text { questions, rhetorical and others }\end{array}$ \\
\hline 6 & $\begin{array}{l}\text { Data commentary, Moves and } \\
\text { submoves }\end{array}$ & $\begin{array}{l}\text { Language technique: how to write qualifying } \\
\text { statements }\end{array}$ \\
\hline 7 & Acknowledgements /References & Language technique: quotations, tenses \\
\hline 8 & Abstracts & Language technique: how to summarise \\
\hline 9 & Punctuation & \\
\hline & PRACTICE & 20 Hours \\
\hline
\end{tabular}

Seven teams of two to five students wrote a research paper, but only three wrote their papers as real papers to be submitted for publication to an anglophone journal. One 
article was in computer science, one in veterinary science, and another in architecture. For reasons of space, the present study will deal more especially with the last two.

In each group a member was responsible for keeping track of the other members' work. The authors worked in teams for a period of two weeks and met almost daily, except for week-ends which were probably as active as the working days, at least as far as the maturing process was concerned. However, none of the teams signalled any written work being done during week-ends.

8 The many implicit translation procedures which go into the making of an RA are certainly an essential aspect of the evolution and the maturing process of the scientific act. These inter-genre and intermodal translations are also certainly an inherent part of scientific activity considered as a project.

It is significant that the three out of seven teams who completed the final stage of written representation in their scientific project were the only teams whose project was conceptually coherent and well articulated, even if all aspects of textual cohesion were not yet definite. This would support the idea of the written stage being considered as an inherent part of the scientific project itself in spite of all the challenges and difficulties encountered when writing in a foreign language.

\section{Factivity and activity}

10 A first illustration of the translation process as a reflection of scientific activity in the making was provided by the veterinary science RA. The cognitive function in scientific activity has often been said to oscillate between factivity and activity, or to put it differently, between an insistence on facts presented as solid, unassailable, but static elements, and acts presented as evidence of the dynamic efforts of the author(s) to modify and hopefully improve a given state of things.

11 Table 1 recapitulates the main stages in the two-week writing of the veterinary science project and underlines mainly its chronological evolution. Put in a very concise way, the topic of the article is the deep-freezing of horse embryos and the basic claim resulting from experimental findings is that a glycerol+sucrose association is a better cryoprotectant than the conventional glycol+sucrose association. Table 2 shows the 'Practice' phase of the EAP course for the veterinary science team. In accordance with the work procedure chosen, the team alternated stages of RA writing and discussion sessions with the other teams who commented on the veterinarians' written proposals shown in transparencies. The five veterinary scientists originally started from a "facts-is-all" strategy (or rather a "facts-speak-for-themselves" one) and then gradually reached a more "acts-is-all" strategy (or rather an "acts-are-better-described-in-words" strategy). This radical change in representation strategy resulted from discussion between team members and within the EAP group about the most acceptable written form to choose for the RA. The inherent changes in moves and overall pragmatic and communicative strategies are given in the table. What must be said here is that when the writing stage of the project was reached all the preliminary experimental facts had already been established as laboratory-proven evidence.

12 What soon became very apparent in the talks was the readiness of the authors to compromise on anything but the language forms they had adopted for the description of the unfolding of their experimentation. These descriptive passages to appear in the 
Materials and Methods section of the RA were a translation of notes taken during the experimental laboratory work which the team members had agreed to adopt. Table 2 compares the two versions of the same scientific acts, in this particular instance the preliminary preparation of the experiment.

Table 1. Main changes in 14-day evolution of veterinary science RA

\begin{tabular}{|c|c|c|c|c|}
\hline Chronology & Topical evolution & Move analysis* & $\begin{array}{l}\text { Pragmatics and } \\
\text { communication } \\
\text { strategies }\end{array}$ & $\begin{array}{l}\text { Linguistic } \\
\text { realisation }\end{array}$ \\
\hline Days 1-3 & $\begin{array}{l}\text { General agreement } \\
\text { among authors "facts } \\
\text { is all". } \\
\text { Experiment WAS } \\
\text { successful } \\
\text { Ethylene-glycol- } \\
\text { sucrose=bad } \\
\text { Glycerol-sucrose= } \\
\text { good } \\
\text { Provisional title of RA: } \\
\text { "Glycerol as a better } \\
\text { cryoprotectant than } \\
\text { glycol in the freezing } \\
\text { of horse embryos" }\end{array}$ & $\begin{array}{l}\text { Agreement to write a } \\
\text { short RA } \\
\text { - Especially short } \\
\text { Intro, Results and } \\
\text { Discussion sections } \\
\text { - Long M\&M** } \\
\text { section: "How we did } \\
\text { it matters more" } \\
\text { Main move: describe } \\
\text { data collection } \\
1^{\text {st } \quad \text { sub-move: }} \\
\text { indicate data source } \\
2^{\text {nd } \quad \text { sub-move: }} \\
\text { indicate data size }\end{array}$ & $\begin{array}{l}\text { - Use as many } \\
\text { photos as possible } \\
(10) \text {. } \\
\text { - Write very short } \\
\text { Intro. } \\
\text { - Seek agreement } \\
\text { about the } \\
\text { phrasing of a few } \\
\text { key sentences. } \\
\text { - Paragraphs } \\
\text { flagged by main } \\
\text { findings used as } \\
\text { titles. }\end{array}$ & $\begin{array}{l}\text { Agreement } \\
\text { found to use } \\
\text { mostly } \\
\text { passive forms } \\
\text { to insist on } \\
\text { results, not } \\
\text { on who did it } \\
\text { or how it was } \\
\text { done. } \\
\text { e.g. "the } 23 \\
\text { embryos } \\
\text { were } \\
\text { assigned } \\
\text { firstly to two } \\
\text { treatment } \\
\text { groups in } \\
\text { stratified } \\
\text { random } \\
\text { fashion." }\end{array}$ \\
\hline
\end{tabular}




\begin{tabular}{|c|c|c|c|c|}
\hline Days 4-6 & $\begin{array}{l}\text { Recognition of } \\
\text { usefulness of } \\
\text { comparative } \\
\text { approach. } \\
\text { Need to include more } \\
\text { detailed description of } \\
\text { batch of } \\
\text { conventionally frozen } \\
\text { embryos in } \\
\text { experiment } \\
\text { General evolution } \\
\text { "Our method is best, at } \\
\text { least compared to } \\
\text { another one". }\end{array}$ & $\begin{array}{l}\text { Introduction made } \\
\text { longer to include } \\
\text { interview of main } \\
\text { competing research } \\
\text { procedure } \\
\text { M\&M. lengthened } \\
\text { even more to include } \\
\text { defining } \\
\text { terminologies, e.g., } \\
\text { "Quality score } 2 \text { is in } \\
\text { the classification } \\
\text { system used by M. } \\
\text { and S. (1988)" } \\
\text { (competing fellow } \\
\text { researchers) }\end{array}$ & $\begin{array}{l}\text { In M\&M. section: } \\
\text { Fewer } \\
\text { illustrations, more } \\
\text { contrastive verbal } \\
\text { descriptions of } \\
\text { team's } \\
\text { experimental } \\
\text { procedure; e.g., } \\
\text { "Whereas X. and } \\
\text { Y. used ..., we } \\
\text { chose instead ..." } \\
\text { In R. section: } \\
\text { insistence on } \\
\text { description of } \\
\text { successful } \\
\text { batches. } \\
\text { In D. section: } \\
\text { mostly } \\
\text { quantitative } \\
\text { evaluation of own } \\
\text { team's results } \\
\text { relative } \\
\text { competing team's } \\
\text { results. }\end{array}$ & $\begin{array}{l}\text { In I. section: } \\
\text { Use of active } \\
\text { forms (we } \\
\text { have shown } \\
\text { that...) to } \\
\text { allude to } \\
\text { team's } \\
\text { actions } \\
\text { Use of passive } \\
\text { forms to } \\
\text { describe } \\
\text { competing } \\
\text { team's results } \\
\text { (mostly } \\
\text { contrasting } \\
\text { figures) }\end{array}$ \\
\hline Days 7-9 & $\begin{array}{l}\text { New and final main } \\
\text { title: "Effects of } \\
\text { sucrose in diluting } \\
\text { glycerol or ethylene } \\
\text { glycol after thawing pf } \\
\text { frozen day } 6.25 \text { horse } \\
\text { embryos" }\end{array}$ & $\begin{array}{l}\text { Both I. and M\&M. to } \\
\text { underline } \\
\text { comparative } \\
\text { approach of the } \\
\text { addition of sucrose in } \\
\text { competing team } \\
\text { "glycol" approach } \\
\text { and own team's } \\
\text { "glycerol" approach. } \\
\text { In R. section: Main } \\
\text { move: indicating } \\
\text { consistent } \\
\text { observation } \\
\text { Sub-move: indicating } \\
\text { specific observations }\end{array}$ & $\begin{array}{l}\text { M\&M. sections } \\
\text { made longer. } \\
\text { Beginning of } \\
\text { previous } \\
\text { section } \\
\text { transferred to } \\
\text { Intro: "The } \\
\text { purpose of the } \\
\text { present study is } \\
\text { to..." }\end{array}$ & $\begin{array}{l}\text { Complete } \\
\text { rewrite of R. } \\
\text { section } \\
\text { Systematic } \\
\text { 'dual' } \\
\text { approach } \\
\text { adopted: } \\
\text { "When } \\
\text { associated to } \\
\text { glycol, the } \\
\text { results are ... } \\
\text { However, } \\
\text { when } \\
\text { associated to } \\
\text { glycerol, the } \\
\text { results are..." } \\
\text { How } \\
\text { choose, to } \\
\text { isolate, } \\
\text { compare, } \\
\text { contrast, } \\
\text { oppose..." }\end{array}$ \\
\hline
\end{tabular}




\begin{tabular}{|c|c|c|c|c|}
\hline Days $10-14$ & $\begin{array}{l}\text { Addition of short } \\
\text { complementary } \\
\text { subtitle: "Microscope } \\
\text { studies of } \\
\text { cryopreserved horse } \\
\text { embryos" + key words } \\
\text { The final impression } \\
\text { conveyed is a much } \\
\text { less triumphant } \\
\text { statement (compared } \\
\text { with provisional title). }\end{array}$ & $\begin{array}{l}\text { The THESIS- } \\
\text { ANTITHESIS- } \\
\text { SYNTESIS (or Former } \\
\text { Discourse-Present } \\
\text { Discourse-State of } \\
\text { the Art) pattern is to } \\
\text { be found explicitly or } \\
\text { implicitly in all } \\
\text { IMMRD sections. }\end{array}$ & $\begin{array}{l}\text { Need to draw } \\
\text { more } \\
\text { intermediary } \\
\text { conclusions (in } \\
\text { summary/to sum } \\
\text { it all/this leads us } \\
\text { to say, at this } \\
\text { stage/ etc.) } \\
\text { Fewer } \\
\text { illustrations } \\
\text { retained ( } 2 \text { tables } \\
\text { only) }\end{array}$ & $\begin{array}{l}\text { - Wide use of } \\
\text { discourse } \\
\text { adjuncts: } \\
\text { "first, second, } \\
\text { thirdly", } \\
\text { indicating } \\
\text { continuity of } \\
\text { orientation } \\
\text { between } \\
\text { different } \\
\text { paragraphs. } \\
\text { - Main } \\
\text { hedging } \\
\text { devices: use } \\
\text { of qualifying } \\
\text { adverbs and } \\
\text { change of } \\
\text { modals ('can' } \\
\text { becoming } \\
\text { 'might' } \\
\text { wherever } \\
\text { possible) }\end{array}$ \\
\hline
\end{tabular}

*The description of some of the moves is taken from Nwogu (1997)

** Introduction, Materials \& Methods, Results, Discussion

Table 2

\begin{tabular}{|l|l|}
\hline Lab work stage & Written representation stage \\
\hline $\begin{array}{l}\text { Embryo } \\
\text { collection }\end{array}$ & Embryo collection \\
\hline
\end{tabular}




\begin{tabular}{|c|c|}
\hline $\begin{array}{l}\text { Collect E. } \\
\text { following } \\
\text { Lagneaux } \\
\text { method } \\
\text { Ultrasound } \\
\text { monitoring of } \\
\text { E. development } \\
\text { every } 12 \text { hours. } \\
\text { Wash E. four } \\
\text { times in PBS } \\
\text { medium } \\
\text { Assess Shape } \\
\text { and size of E. } \\
\text { Sort out E. as } \\
\text { to } \\
\text { development } \\
\text { stage } \\
\text { Classify } \\
\text { following } \\
\text { McKinnon \& } \\
\text { Squires }\end{array}$ & $\begin{array}{l}\text { A total of } 23 \text { embryos were collected from Trotter, Pottock Pony and Welsh } \\
\text { Pony mares by a transcervical flush of the uterus with PBS containing } 0.2 \% \mathrm{w} / \\
\text { v bovine serum albumin (BSA) at } 37^{\circ} \mathrm{C} \text { (I.M.V., l'Aigle, France) as previously } \\
\text { described (Lagneaux et al. 1988). Non-surgical embryo collections were } \\
\text { performed } 6 \text { days after diagnosis of spontaneous ovulation checked every } 12 \\
\text { hours by ultrasound examination. Therefore, the expected age of embryos was } \\
6.25 \pm 0.25 \text { days. Embryos recovered from the flushing medium were washed } \\
\text { four times in PBS medium containing } 0.4 \% \mathrm{w} / \mathrm{v} \text { (BSA) (Medium «F1 ») (I.M.V., } \\
\text { I'Aigle, France) at } 22^{\circ} \mathrm{C} \text {, under a laminar flow hood. Their morphology was } \\
\text { then evaluated with an inverted microscope, and their total diameters, } \\
\text { including the zona pellucida, were measured using an eyepiece micrometer. All } \\
\text { embryos were judged to be morphologically normal and had quality score } 1 \\
\text { (excellent) or } 2 \text { (good) in the classification system used by McKinnon \& Squires } \\
(1988 \text { ). They were ranged in development stages from morula (n=6) to early } \\
\text { blastocysts ( } \mathrm{n}=17 \text { ) with diameters from } 151 \text { to } 211 \mu \text { m (mean } \pm \text { s.d.: } 176.1 \pm \\
13.3 \mu \mathrm{m} \text { ) }\end{array}$ \\
\hline
\end{tabular}

Although the different actions listed in the first column may read like the agenda prepared prior to the lab experimental work, they include results, albeit in condensed form: the ultrasound monitoring of the embryos had not necessarily been scheduled to happen every 12 hours, the embryos were not supposed to need to be washed four times in PBS before the experiment actually happened, etc.

What is worth noticing in the written version is which information is given verbatim, detailed, adapted/translated or not given at all. The RA is obviously addressed to experienced peer researchers having state-of-the-art knowledge of the domain, consequently, such presumably basic lab procedures as how to collect embryos nonsurgically or what a laminar flow hood is are not even brought up, not to mention the definitions of presumably elementary notions like 'spontaneous ovulation', 'zona pellucida', etc. The writing of an article for students or lay readers in a foreign language would certainly have posed insurmountable difficulties to the five non-native researchers and the amount of shared knowledge, mathematical formulae and universally agreed measurement units are a welcome element to all NNS researchers having to present their work in English (Sionis 1995).

The veterinary science writers did not report their language interactions during laboratory work, but one can presume that these contributed to the fuller, more detailed written passage in the RA. Possible language exchanges might for instance bear on quantities, choice of adequate name for an observed phenomenon, etc. Again this is only EAP teacher's surmise as the team did not record and transcribe their conversations as they carried out their experimental work.

What also becomes apparent, both in the sketchy notes and their fuller written version, is that the project does not correspond to a series of actions clearly observable in real time 
(Vinck 1995: 154). When questioned as to the unfolding of the sequence of actions the veterinary researchers admitted that contrary to the impression given by the full written version, the preparation of the experiment encompassed a considerably longer period of time than the apparent 6 days mentioned. Momentary failure of apparatus, the ensuing need to renew whole batches of embryos, the non-availability of equipment when needed, etc. are events which did not surface in the written part of their project.

The strength of their claim was originally felt by the authors to be the unquestionable nature of their findings, but it is because they also felt that proven facts, however strong, were not enough to get them accepted by their research community that they engaged in very long and critical discussion on how to present their work. In doing so in a second language, they ran the risk of somewhat losing control of their project because of the many different communication strategies involved in a more complex type of presentation. The other risk was lessening the impact of their claim. This is what happened to a certain extent when, for example, the need to assess the work of other researchers, led them gradually to forsake the original title of their RA -an essential component of any scientific project which, because of the widespread practice among scientists of first consulting the indexed titles of RAs in specialised journals, could even result in their RA not being read at all by other researchers.

In this instance, interaction through discussion resulted in a change of topical focus for the whole project from an 'A-better-than-B' pattern (Glycerol better than glycol) to a considerably different and more complex 'Effects-of-C-on-A-and-B' pattern (Sucrose diluting glycerol or glycol). The team's original purpose was thus drastically altered. By placing A (glycerol) on the same footage as B (glycol), and indirectly, or involuntarily, highlighting the role of $C$ (sucrose) by introducing it as a common factor between A and $\mathrm{B}$, the authors complied with representational procedures they felt were more likely to be accepted by their research community. The authors confirmed that they would have chosen the A-better-than-B pattern in the case of an oral paper (as they did with the EAP group) knowing that the audience would have had the possibility of asking oral questions on the compared effects of sucrose on glycol and glycerol. The adoption of the more complex representation pattern was clearly dictated by the RA genre.

The adoption of different representation patterns then derived from the discussions the team members had amongst themselves and with others. It seems that when the scientific project has reached the stage of being put on paper, the representation process which takes place involves not only the team members themselves but also their social environment (colleagues, friends, relatives, fellow-students, etc.). As Vinck (1995: 173) puts it:

Scientific facts thus result from a wide process of collective production involving as much the laboratory itself as the network of readers and reviewers of utterances [...] Facts are constructed gradually through exchanges and interactions with materials, texts, individuals and equipment. The fact is a final result, not a preexisting thing waiting to be discovered. It is a product resulting from a long and negotiated construction both with things, texts and colleagues. [...] The factivity of the utterance constantly fluctuates. (my translation)

This casts scientific facts and acts in a special perspective. Speaking or writing about a scientific fact is in itself a scientific act which belongs to scientific activity. The changes in the form of an utterance have a direct consequence on the existence of a scientific fact for the outer world of observers and readers of science. Here again Vinck must be quoted: 
Produced by the articulation of multiple texts, apparatus and people to be able to resist criticism, the scientific fact only exists through the network of people, things, knowledge and prior facts. It depends entirely on the circumstances of its production. Its success results from the fact that people perceive it as not having been constructed. (1995: 174)

\section{The architecture project} environment and an 'active' element which would delineate volumes in it also needed to be convincingly established.

\section{2) (Day 3) First oral presentation + questions}

Author 1: "[...] to make you understand the notion of solar landscape, let me show you what happens if I move this desk-lamp above these three piles of books placed on the table. You clearly realise that the volumes, I also mean the shapes, seem to change, look smaller or bigger depending on the shadows cast, on the existing or vanishing shade at the bottom of the books, etc. We would like to demonstrate the fact that the new solar landscape which we call 'Solarscape' is a dynamic notion which can be opposed to the notion of environment, which in this case is static. The piles of books which here figure buildings in a town do not move, of course"

Teacher: This is an essential point you want to make and you'll have to decide where this is going to appear in your written article

Author 1: Yes, of course, and the sunlight being a creator of volumes is a central claim, it is the topic of our research.

Student A: The example you chose, the books and desk-lamp, is well chosen. 
Student B: I suppose this will come at the beginning of your article.

Student C: What is dynamic?, what is static? I still can't understand very well.

\section{the authors' minds and from that point on the authors will slowly assume a less} entrenched position.

\section{3) (Day 4) Second oral presentation + questions}

Author 2: [...] What we want to underline is that the dynamic characteristic of the Solarscape comes from the many different ways you can possibly look at the same buildings and streets. For us a landscape is dynamic -this is why we called the phenomenon 'Solarscape'- but an environment is static. Also, the landscape can be seen by many onlookers. The rays of the sun are like the eyes of one specific onlooker. The way you look at things creates volumes, you create those volumes, and you draw a line between entities (does this word exist in English?) and emptiness.

Student C: This is not very clear to me.

Author 2: It is true that sunlight and Solarscape are closely linked and belong to the environment.

The researchers do not immediately surrender in open space on the perhaps not so crucial distinction between 'active' sunlight and 'passive' landscape. Instead, they introduce a third element, namely the onlooker's selective eye which gives meaning to what he/she beholds. When listeners still express doubt, the day is definitely lost and the whole argument is jettisoned in a spectacular about-face. Clearly, the oral presentation will have served as a testing ground for the written version and, in this particular case, no translation process from one to another genre will even be necessary: the position is recognised as weak and definitely not worth fighting for. However, as the rest of the RA will demonstrate, the surrender will be visible only in the wording of the abstract.

\section{4) (Day 6) Writing the abstract}

First draft submitted to the rest of the group:

Amongst the various studies of urban forms, many are concerned with typo-morphological aspects, possibly combined with historical factors. These studies mainly emphasise the understanding of the urban environment, in terms of design, development, land parcel distribution, and their relations with the morphological aspects and formal characteristics of urban space. Another way to analyse urban forms may consist in examining them as closely related to various environmental factors and to consider these as creators of a specific physical and micro-climatic environment. A classification of the different urban forms in terms of ventilation, light, energy, or sound may be an opportunity to correlate the geometrical and architectural properties of urban space with its environmental specificity.

In the process of inter-genre translation from oral presentation into abstract, the conceptual ambiguity spotted by the other group members (the sunlight as an outer or inner component of the environment) is totally erased. Strangely enough, although the title of the RA is 'Solarscape', or the Sun as Creator of Urban Forms, the specific role of the sunlight in the creation of a new urban landscape is not even mentioned in the abstract. Instead, the authors mention urban forms being related to 'various environmental factors'. This is perhaps an illustration of the influence (in this particular instance, a negative one) of a perceived need to downplay the action of the sunlight on the 
environment and to assimilate it to the environment itself. However, there remains a discrepancy between a rather vaguely written abstract about the action of 'various environmental factors' on urban forms and the body of an RA very specifically dedicated to the action of the sunlight on the way urban designers and town-dwellers can perceive these urban forms. The rest of the RA will clearly indicate that the authors did not surrender on the gist of their project.

The timing of the various EAP exercises certainly played a part in the unfolding of the scientific project not unlike the role played by journal reviewers who, through their comments on submitted manuscripts, often steer whole projects off their original course. In this respect, scientific interaction also concerns those downstream evaluators, who, as colleagues and co-researchers, also cooperate in the scientific project. The strength of interactionism in scientific activity is certainly very real but it may be worth noting that in the present instance, the hard core of the topic was not affected: the RA did remain centred on the action of sunlight on urban forms.

During the first oral presentation, the use of real-world exemplification (the books and desk-lamp) was judged efficient by the authors and this will find its way into another mode and genre.

\section{5) (Day 8) Extract from first draft of written RA}

[...] The Solarscape, by its effects on the lighting or darkening of streets, strongly influences urban space. The sun constantly modifies the giant patchwork of urban areas and definitely belongs to the urban environment. The multiplicity of differently illuminated areas gives a dynamic dimension which justifies the notion of landscape as compared to the notion of environment. One can say that perceived sunlighting, and consequently the solarscape which is closely dependent on it, are both environmental factors. $[\ldots]$

\section{6) (Day 10) Discussion with other teams}

Overall, the concept as worded in the above passage was better accepted by the other teams. Here again the other fellow-students regretted the loss of the books and desk-lamp illustration. The authors agreed on the need to merge, after due adaptation/translation, some aspects of their oral and written presentations, but wanted some help in doing it. This help was provided by more expert writers in the peer group and the EAP teacher. The latest version of the passage to date is as follows:

[...]This instrumental dimension of urban space deserves attention and study. We must first keep in mind that sunlight is the necessary condition for its realisation. Then, one can describe the city as a real solar device in which its morphology, materials and volume fully participate in the sunlighting of the urban environment. In the present study we will look at the relationship existing between urban forms and sunlighting.

The Solarscape

Judging by its effects on the lighting or darkening of streets, the sun strongly influences urban space. The built-up areas mask the sun which, in its turn, delineates forms and frameworks. The sun constantly weaves and unweaves the giant patchwork of urban areas and is part and parcel of the town environment. A public square can be noticed because it " is flooded in sun ", a less bounded area will allow the sun to enter deeper, a street intersection will become visible because of a dot of sunlight illuminating an otherwise dark street. Some interesting analyses of urban space have been conducted about the city seen by an observer standing or walking at street level. These 
analyses contributed to defining the notion of urban landscape [1] [2]. For the pedestrian moving in urban space, the sun plays such an essential part in the making of the urban landscape that one can really speak of Solarscape. We will define the notion of Solarscape in two possible ways which seem fundamental to us.

First, from a subjective viewpoint, as the totality of sunlight which is cast at a given place and which is therefore visible only for a given observer. The Solarscape is not only the landscape of urban space volumes, it is also a new geometry which modifies the form of the city.

Then, from a more diverse viewpoint, the Solarscape is very dynamic at different levels. The possible multiplicity of viewpoints gives a dynamic dimension which justifies the notion of landscape as compared to the notion of environment. Even if we stopped the movement of the sun at a given moment, a pedestrian walking the streets of a city would be able to see new perspectives opening and would discover new sunlit spots punctuating the open space and spreading on walls and the ground which make up the new boundaries of space. Even without moving about, the observation of the Solarscape shows it is being modified almost continuously depending as it does on the motion of the earth around the Sun. This induces a new distribution of sunlight in interaction with the overall mask of urban buildings.

One can say that perceived sunlighting, and consequently the Solarscape which is closely dependent on it, are both environmental factors. It seems to us, in view of what we have written previously, that the Solarscape could also be really considered as one component of urban and architectural forms.

\section{Conclusion} the chronological evolution of a project. The characteristics of each different genre and mode had to be translated into components which are universally agreed to belong to a target-genre: the RA.

The interactionist theory was also supported by the following observations.

Collective action, and especially interaction between authors and student-group, contributed to the construction of an RA which is not only a genre likely to be accepted by one's own research discourse community (Swales 1990) on the basis of conceptual strength, state-of-the-art advancement, informational content, etc., but also a social construct including academic learning needs (the EAP context of acquiring language and communication skills), the requirements of relative scientific vulgarisation (the EAP fellow-students were specialists of their own domains but these domains overlapped in a number of areas with those of the authors, among which the criteria of good, orderly, rigorous scientific representation were prominent), etc. 

its organisational context". In my view, this is the farthest one can go in recognising the constructivistic role of written and other representational modes in scientific activity. 'Organisational context' must, of course, be understood as covering the many networks on which scientists depend for their work (national or international research teams, specialists' journals, laboratory organisation, administrative and financial constraints, etc.). In the light of the present EAP experience, and in spite of the reservations expressed above as to the fundamentally unalterable findings and topics, the phrase holds true and illustrates the need for coherent representation modes. This includes coherent writing style in a foreign language (the EAP students did not translate a text pre-written in their native language into English), to serve presumably coherent scientific concepts. Conversely, the phrase also implies that badly conceived scientific constructs are to be rethought when the touchstone of the representational mode finds them wanting. In both cases, the responsibility of the EAP teacher goes much beyond a superficial control of the language, e.g., for grammar and lexical correctness only.

The author wishes to thank his fellow researchers and students who participated in the 1998-99 EAP course and more especially those who agreed to have their hesitations and soul-searching displayed so openly: J.-F. Bruyas, J.-P. Sanson, I. Battut, F. Fiéni, D. Tainturier, D. Follut and D. Groleau.

\section{BIBLIOGRAPHY}

Amman, K. \& K. Knorr. 1988. “Thinking through Talk: An ethnographic study of a molecular biology laboratory". In Hargens L., R. Jones and A. Pickering, Knowledge and Society: Studies in the Sociology of Science, Past and Present, JAI Press.

Callon, M. \& B. Latour. 1991. La Science telle qu'elle se fait. Paris: La Découverte.

Fujimora, J. 1987. "Constructing 'do-able' problems in cancer research: Articulating alignment". Social Studies of Sciences 17, 257-293.

Fujimora, J. 1992. “Crafting science: Standardized packages, boundary objects and 'translation"'. In Pickering A. (ed.), Science as Practice and Culture. Chicago: Chicago University Press. 
Latour, B. \& S. Woolgar. 1988. La vie de laboratoire, la production des faits scientifiques. Paris: La Découverte.

Lynch, M. 1985. Art and Artifact in Laboratory Science. A Study of Shop Work and Shop Talk in a Research Laboratory. London: Routledge and Kegan Paul.

Nwogu, K. N. 1997. "The medical research paper: Structure and functions”. English for Specific Purposes 16/2, 119-138.

Pickering, A. (ed.). 1992. Science as Practice and Culture. Chicago: Chicago University Press.

Sionis, C. 1995. "Communication strategies in the writing of scientific research articles by nonnative users of English". English for Specific Purposes 1/2, 99-113.

Star, L. \& J. Griesemer. 1989. “Institutional ecology, 'Translations' and Boundary Objects: Amateurs and professionals in Berkeley's Museum of vertebrate zoology, 1907-1939" Social Studies of Science 19, 387-420.

Strauss, A. L. \& L. Rainwater. 1962. The Professional Scientist: A Study of American Chemist. Chicago: Aldine.

Swales, J. 1990. Genre Analysis. Cambridge: Cambridge University Press.

Vinck, D. 1992. Du laboratoire aux réseaux. Le travail scientifique en mutation. Luxembourg: Office des Publications de la CCE.

Vinck, D. 1995. Sociologie des sciences. Paris: A. Colin.

\section{NOTES}

1. The article is more complete version of the presentation: "Interaction With Peers And The Outer World In The Construction of A Scientific Research Article", Proceedings 12th LSP Symposium, Bolzen/Bolzano, Italy, August, 1999.

\section{ABSTRACTS}

The paper is derived from the observation of the work of group of established French scientists who attended an English for Academic Purposes (EAP) course in the writing of research papers in English. Among the many useful, and often unexpected, observations was the constant need for the scientist who is several persons at a time and in alternation - a teacher in his own domain, a disputed and disputing member of a team, a vulgariser of his research with specialists of other domains or even at home, etc. - to engage constantly in intermodal and inter-genre translation depending on changing situations, milieus, times of the day, etc. The paper tries to show how this intermodal and inter-genre translation process occurred during the EAP course and defends the idea that it is an inherent and essential component in the evolution of conceptual knowledge and its representation.

L'article découle de l'observation du travail d'un groupe de scientifiques français confirmés qui participaient à un cours d'anglais pour universitaires orienté vers la rédaction d'articles de 
recherche. Le scientifique doit être plusieurs personnes simultanément et en alternance: enseignant de son propre domaine, membre contesté et contestataire d'une équipe, vulgarisateur de sa recherche pour des spécialistes d'autres domaines ou même pour ses proches, etc. L'une des observations nombreuses et souvent inattendues de l'étude est le besoin pour ce scientifique de se livrer constamment à une traduction intermodale et intergénérique en fonction des changements de situations, de milieux, de moments de la journée, etc. L'article tente de montrer le fonctionnement de ce processus de traduction pendant le cours d'anglais pour universitaires et de défendre l'idée que ce processus est une composante inhérente et essentielle de l'évolution du savoir conceptuel et de sa représentation.

INDEX

Keywords: EAP, genre, mode, scientific discourse

Mots-clés: anglais universitaire, discours scientifique, genre, mode

AUTHOR

CLAUDE SIONIS 